\title{
Initial vs. non-initial placement of agent constructions in spoken clauses: A corpus-based study of language production under time pressure
}

\author{
Koenraad Kuiper $^{\mathrm{a}, *}$, Neda Bimesl ${ }^{\mathrm{b}}$, Gerard Kempen ${ }^{\mathrm{c}}$, Masayoshi Ogino ${ }^{\mathrm{a}}$ \\ ${ }^{a}$ The University of Canterbury, Christchurch, New Zealand \\ ${ }^{\mathrm{b}}$ Kish Language Institute of Science and Technology, Tabriz, Iran \\ ${ }^{\mathrm{c}}$ Max Planck Institute for Psycholinguistics, Nijmegen, The Netherlands
}

\section{A R T I C L E I N F O}

\section{Article history:}

Received 10 December 2016

Received in revised form 9 May 2017

Accepted 3 June 2017

Available online 23 June 2017

\section{Keywords:}

Sports commentary

Rightward placement of subjects

Japanese

Persian

Speech production

Functional linguistics

\begin{abstract}
A B S T R A C T
In this exploratory study we test the hypothesis that the retrieval from memory of proper noun agents (PNAs) under processing pressure causes a greater proportion of such semantic arguments to be placed to the right of the initial position in a clause than would be the case if such retrieval from memory were not necessary. This effect is manifest in sports commentary. Processing pressure on sports commentators is modulated by the speed at which the sport is played and reported. Non-initial placement is also facilitated by formulae which have slots in non-initial position. It follows that the non-initial placement of PNAs is not always semantically or pragmatically motivated. This finding therefore runs counter to a strong form of the functionalist hypothesis that syntactic choices available in the systemic structure of the syntax of a language offer solely semantic or pragmatic choices. It is an open question in a weak functionalist account of language and language use how processing and communicative functions interact in general.
\end{abstract}

(c) 2017 Elsevier Ltd. All rights reserved.

\section{Introduction}

A functional account of language supposes that the means, as represented by the formal aspects of language: its lexis, morphology and syntax, serve the communicative ends of speakers. ${ }^{1}$ For example, passive constructions demote the agent argument and promote the theme argument because the speaker wishes to place the theme argument into focus or topic position (Payne, 1997, p. 204). Because the information structure of sentences often serves the purpose of providing given

\footnotetext{
* Corresponding author. 22 Patanga Crescent, Thorndon, Wellington 6011, New Zealand.

E-mail addresses: Koenraad.Kuiper@canterbury.ac.nz (K. Kuiper), n.bimesl@yahoo.com (N. Bimesl), gerard.kempen@mpi.nl (G. Kempen), masayoshi. ogino@canterbury.ac.nz (M. Ogino).

1 The following quotations suggest that (although universal quantifiers are missing but implied) that a number of functional theories of language suppose that language generation is motivated entirely by functional considerations. 'Syntax is there in order to allow for the construction of formal structures by means of which complex meanings can be expressed.' (Dik, 1981, p. 2)

'Since natural language is an instrument used for communicative purposes, there is little point in considering its properties in abstraction from the functional uses to which it is put.' (Butler, 1998, p. 19)

'A language ... is a system for making meanings: a semantic system, with other systems for encoding the meanings it produces.'(Halliday, 1985, p. xvii)

'One of the basic principles of functional linguistics is that clause-internal morpho-syntax can only be understood with reference to semantic and pragmatic function of its constituent units.' (Foley and Van Valin, 1984, p. 14).
} 
information earlier than new information (Halliday, 1985, p. 278), the topic of a proposition comes before a comment. Hence the functional possibilities afforded by the passive construction. Fronting can also serve to focus an argument or adjunct.

A functional theory of language can be formulated strongly as follows:

all the options made available by the lexis, morphology and syntax of a language serve communicative ends, i.e. are semantically or pragmatically motivated;

or it can be formulated weakly as follows:

some but not all options made available by the lexis, morphology and syntax of a language serve communicative ends.

In this paper we support the view that there are syntactic phenomena which, in one communicative context and on the balance of probabilities, appear not to serve purely communicative ends thus supporting the weak form of a functional analysis.

Since Miller and Chomsky (1963) it has been known that the formal properties of the syntax of a language and the human language parser with its dependence on a limited working memory interact to limit the acceptability of some kinds of syntactic constructions including centre-embedding. Hawkins (1990) proposes that some word order properties are a result of human parsing limitations. Hawkins (1994) also proposes that short constituents tend to be placed in syntactic sequences before long constituents, although that is contested for Japanese (Chang, 2009; Yamashita and Chang, 2001). Bock and Warren (1985) argue that the conceptual accessibility of an NP affects the grammatical role assigned to the NP-e.g. subject vs. object —, thus indirectly determining the its position in the clause. Kempen and Harbusch (2004) observe that conceptual accessibility can also influence the linear order of clause constituents directly, that is, without the intervention of grammatical function assignment. More specifically Ackema and Neeleman (2002) propose that the human parser is responsible for the asymmetric properties of movement to leftward initial position vs. movement to non-initial positions (Kayne, 1994; Ross, 1967). These theories suggest that, in a competition between the constraints of the syntax and the constraints on human speech processing, the processor often wins. ${ }^{2}$

In this paper we compare the predictions of two hypotheses: the processing hypothesis which proposes that, in the speech of sports commentators, some syntactic ordering choices are motivated, as argued by Green (1980), by processing constraints on speech production challenging the strong functional theory of speech production. ${ }^{3}$ Our test data bear on the non-clause-initial placement of proper noun agents and actors (PNAs) in broadcast sports commentary speech. The selected genres have been chosen because they allow for a measure of control on time pressure on speakers. Where, in previous work, proposals about non-initial placement of PNAs have been made on the basis of observations of the generic character of sports commentary and were based on English commentary regardless of the pace of the sport, the present study takes into consideration the pace of the sport, the number of PNAs in the commentary and the language of the commentary (we use Persian and Japanese data alongside English data). Furthermore, we present quantitative data, drawn from two different sports: football and horse racing.

Our leading research questions are therefore:

1. Is a strong form of the functionalist hypothesis falsified by the rightward placement of PNAs in the commentary of medium- and fast-paced sports?

2. What strategies are adopted by commentators of medium- and fast-paced sports for the rightward placement of PNAs?

3. How well do functionalist and processing theories account for the rightward placement of PNAs?

The study has the following limitations:

1. Its data set is drawn from the commentary of two sports and three languages.

2. The data consists of just on a thousand utterances.

The data set of formulae is restricted to English and the extraction of formulae is by native intuition rather than by computational means.

\subsection{Commentary speech ${ }^{4}$}

\subsubsection{The context}

In functional accounts of language such as that of Systemic Functional Grammar (Halliday and Matthiessen, 2004), Dik's functional grammar (Dik, 1981), Hengeveld and Mackenzie's (2008) functional discourse grammar ${ }^{5}$ or Foley \& Van Valin's

\footnotetext{
${ }^{2}$ We assume large-scale overlap between the cognitive processing modules underlying language production and language comprehension (Kempen, 2000; Kempen et al., 2012).

${ }^{3}$ Both hypotheses are functional in the general sense but not in the narrow sense of the strong hypothesis proposed earlier.

${ }^{4}$ American English speakers use the term 'sport announcer' whereas English and antipodean speakers use the term 'sports commentator' for those who provide live sports commentary.

${ }^{5}$ Hengeveld and Mackenzie (2008) state that their functional model is congruent with speech production models. But note that our results suggest that the processing priorities of the speaker may take precedence over the processing interests of the hearer, i.e. of language comprehension, as Wasow (1997) also suggests.
} 
functional syntax (Foley and Van Valin, 1984), the context and its relationship to the communicative intent of the speaker play significant roles. So what is the context for a sports commentator and what is the commentator's communicative intent? Sports commentators watch sports events either live or on a television monitor. Their communicative task is to convey to their audience in real time the maximum amount of relevant information about what is happening during the sports event. According to Ferguson (1983, p.150), commentary is 'oral reporting of an on-going activity, combined with provision of background information and interpretation'. On this basis, commentary can be split into two different phases which are distinguishable from each other. According to Holmes (2001), play-by-play commentary describes the action itself. Colour commentary, on the other hand, refers to more 'discursive' and 'leisurely' speech with which commentators fill the time between periods of action. Delin (2000) suggests that play-by-play commentary forms the main structure, the backbone, of the commentary because it describes immediately what is going on which is the main purpose of a commentary. ${ }^{6}$ Mackenzie (2005) also divides football commentary into two phases: event-related, which happens during the play and non-eventrelated which has to do with giving summaries and information whenever play stops.

In functional terms, play-by-play commentary involves the provision of almost entirely new information. Occasionally play-by-play commentary draws on what has happened previously or on the identification of participants mentioned immediately before the current utterance. The function of the commentator's talk is thus to convey new information, particularly the names of currently relevant participants: players in games, horses in races. These participants are, functionally, usually either agents or actors. ${ }^{7}$ Football player X dribbles the ball, passes the ball to player Y, takes a shot at goal and so forth. Horse $\mathrm{X}$ is in the lead, drops back in the field. In some sports, the majority of utterances are produced to name the player (or horse).

Sports have different mean speeds at which the events in them proceed. Some sports are inherently faster while some are inherently slower. ${ }^{8}$ We do not mean that the speed at which the sport itself is played is fast or slow but that the pace at which significant episodes occur is fast or slow. For example, long track speed skating is in itself fast in that skaters are moving rapidly but it involves few significant episodes. Slow sports can, however, contain fast episodes and fast sports can contain slow episodes. For example, cricket is inherently slow in that its major episodes occur at relatively long intervals; bowlers bowling a ball at batsmen are separated by considerable time intervals during which little of note happens. Ice hockey on the other hand is inherently fast while the game is being played. Many episodes are crammed into short time periods but there are also periods, for example, when a penalty has been awarded and the player who is to serve the penalty is skating to the penalty box, when nothing of note takes place (Kuiper and Haggo,1985).

The task of a commentator of fast sports is to be fluent enough to keep up with the pace of what is happening in the visual field as otherwise the commentator would miss some episodes of the game. So the faster the sport, the more difficult it is for the commentator to speak and report immediately what is taking place (Kuiper, 1996).

What linguistic reflexes are there of the processing pressure associated with different speeds at which a sport proceeds? One reflex of the relative speed of a sport is the number of seconds per clause in its commentary. In the data discussed below, the horse racing commentators produce a spoken clause every three and a half seconds, whereas the football commentators average one spoken clause every eight seconds. By contrast on-line commentators of rugby and association football in our

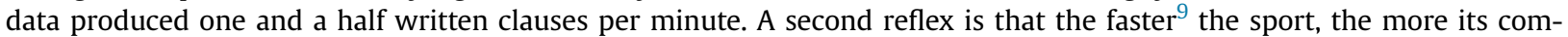
mentary will be constructed of formulae (Kuiper, 1996). In our English race calling data to be reported below, 84\% of all clauses are formulaic (Wray, 2002); the English football commentary is $46 \%$ formulaic while the football written commentary is $45 \%$ formulaic. ${ }^{10}$ Third, in fast sports there is no colour commentary, for example in our horse race calling data. In our data taken from the spoken commentary of medium-paced sports, colour commentary accounted for 35\% of the utterances of the commentators. However there are football commentaries in which this percentage is higher, particularly if two commentators are involved. In the commentary of slow sports such as cricket and golf commentary, which we have not examined in this paper, there is a great deal of colour commentary between significant events since these events are far enough apart to allow for colour commentary to be the bulk of the commentary. In a five kilometre speed skating race two commentators provided only colour commentary since there were no immediately significant events to relate. ${ }^{11}$

We now take a closer look at the task of the commentator of a medium-paced sport and a fast-paced sport. The commentator watches the sport and his task is to relate the significant events he sees to the listeners and watchers. Every event is both a new event and a conventional event taken from an inventory of such events which are the 'moves' of the sport. Football players dribble the ball, they are tackled, they pass the ball, they shoot at goal. But the particular order of these events and the particular player performing these events are not predictable. Horses gallop around the track in various positions relative to the current position of the field of runners on the course, the rails at the side of the course and other individual

\footnotetext{
6 This is not true of all sports commentaries. In some, as we shall suggest later, the majority of the commentary is in colour mode.

7 We take the agent role assigned to an argument to designate one who acts upon a patient argument while actors do not. This allows us to differentiate football players who kick a ball from race horses which run. The first is an agent while the second is an actor. We have subsumed Actor under Agent.

8 Simple metrics could be devised to measure the speed of significant events. Play-by-play commentary would be one way to assess this. Native viewers would also be able to indicate what constitutes a significant event.

9 e.g. https://www.youtube.com/watch?v=uSk7kAfeu2I.

10 See below for a discussion of formulaic utterances.

11 https://www.youtube.com/watch?v=Pq-MxtnYOds.
} 
horses. In this sense every event is a new current event consisting of a new player or horse and a new action which that player or horse is performing.

The task of the play-by-play commentator is thus to identify the move in which the player or horse is involved and the name of the player or horse. The selection of PNAs is mediated by the fact that the names are stored in a commentator's memory and must be retrieved from memory when an event in which the PNA is participating is being related. Previous experimental-psychological research has found that the retrieval of proper nouns is more difficult than the retrieval of common nouns thus adding to the commentator's speech production difficulties (Cohen and Burke, 1993; Hanley, 2011; Schwartz, 2014). Furthermore, the time course for the retrieval of PNAs in commentary speech is longer than retrieving proper names from memory in the absence of their being in the visual field (such as the remembering the name of a distant cousin in a conversation) because, in the case of commentary speech, the entity having the name must always first be identified in the visual field. Such identification has its own additional time course.

We now examine the consequential processes of speech planning for sports commentators. We assert that much speech planning for sports commentary is governed by a requirement that is not one which governs most other forms of speech planning, namely a commentator is required to attend to what appears in his visual field and speak directly about what happens there in real time. This attention to externally perceived events is modulated, as we suggested earlier, by cultural ways of seeing these events in the visual field. In other words, planning a commentary discourse involves the commentator selecting and composing linguistic expressions which refer to the culturally appropriate concurrent perceptions of events in the visual field.

Much of what is conventionally expressed in a sports commentary is immediately manifest in the visual field: where players are on a football field, whether a football player has taken a shot at goal, what the colours of the jockey of the leading horse are, which of the marker pegs around the course the field of horses is currently passing. However some of what is required to be expressed is not immediately manifest. While the name of a football player is on the back of their playing strip, the commentator is either seated in the commentary box where the names are not always clear or watching the game on a monitor where the image is usually not in close-up mode. Matters to be related but which are not immediately manifest require extra processing time in the form of inference or lookup.

Relating sporting events in culturally conventional modes of expression has two aspects: planning and lexical selection. Planning depends on the sport. Planning is also short-term, given that it must be governed by changing visual input. In racing commentary the great majority of events is governed by the convention that each event relates the location of a named horse relative to other horses, the location being given in two dimensions, before or after another horse or in relation to the rail, being either closer to or further out from the rail. The location of each horse is given in first-to-last order. In football, events are more complex; the focus, however, is usually to name the player who is currently in possession of the football.

Lexical selection involved in the current plan (Levelt, 1989) can be implemented in two ways: either by selecting individual words which are associated with the relevant lexical concepts, or selecting formulae, often as well as individual words. After lexical selection, individual words must be organized into syntactic constituents and then linearized. Formulae are already syntactic constituents and may well already be linearized. Take, for example, the horse racing formula Horse 1 is followed (then/there) by horse 2 . This formula only occurs in the passive form for reasons to be elucidated later.

We take a formula to be a phrasal (multiword) lexical item with associated conditions of use. In the case of sports commentary, such conditions of use include the fact that they are sport-specific and, beyond that, that they perform particular roles in a sports commentary. For example, in horse race calling, there are loop formulae which are uttered when the commentator has reached the tail of the field and is looping back to the leading runners. Such formulae often indicate where in the race the field of runners currently is, e.g. they pass the 1600 mark, they turn for home. The lexical selection of formulae is governed by two factors. The first factor is that the conditions of use of the formula are congruent with the current speech plan, i.e. that a horse is leading by two lengths has a congruent formula in the lead by two lengths is $<$ horse name $>$. The horse name is a slot into which the commentator places the name of a horse. The second factor in his naming of the horses and their positions in the field of runners is the pressure the race caller is under to maintain fluency. Since all sports have conventional episodes, we can expect the speed of the sport, placing pressure as it does on the speech planning and production of the commentator, to be a significant factor leading to a higher incidence of formulae in the commentary of fast-paced sports than of medium-paced or slow sports.

\subsubsection{Syntactic facilitation of fluent speech in sports commentary}

Various syntactic devices are available to facilitate fluent speech. Analyzing baseball and tennis commentaries, Ferguson (1983) provides a taxonomic model for the analysis of this kind of talk. His model may be interpreted as a processing model which includes simplification, namely omission of constituents such as a pragmatically predictable pronoun subject, copula, and subject plus copula, and subject postposition. Pro drop and verb omission involve saying more with less since the listeners or viewers can fill in the omitted constituents from context. Both Green (1980) and Kuiper (1996) have proposed that syntactic inversion such as passive constructions and preposing around be, are ways of postponing the PNA, allowing commentators more time to retrieve from memory the names of players and horses which fill what is canonically initial position. ${ }^{12}$

\footnotetext{
12 Other syntactic constructions noted by Ferguson (1983) as characteristic of sports commentary appear to result from the nature of what is being described: result expressions (for and to phrases), heavy modifiers (brief information with the name of a player) and tense usage. Ferguson also notes the use of routines and formulae in sports commentary.
} 
To provide an initial set of examples from the literature, what follows are some of the English syntactic constructions which allow for non-initial placement of PNAs in English commentary speech. The extent of these examples show that these constructions have been noted for a number of different sports by a number of different investigators.

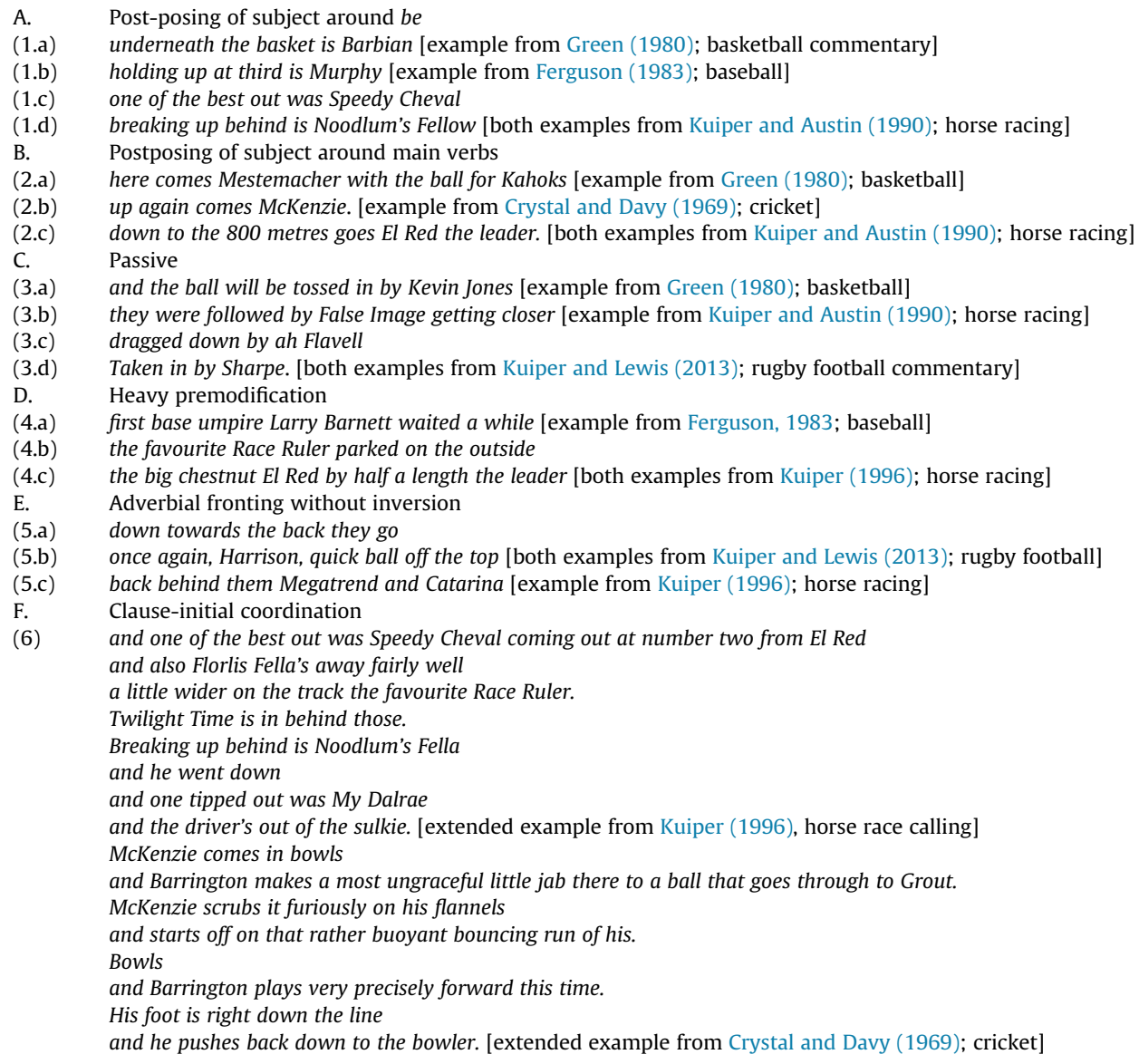

These examples from a variety of play-by-play commentaries in a variety of sports suggest that non-initial placement of a PNAs is a syntactic feature of commentary speech as a text type. A plausible account for this feature of play-by-play commentary is that this "postponing of reference to the name of the player allows him [the commentator] to describe what is directly observable ... while (in real time) remembering or figuring out who "number 30, blond guard" is' (Green, 1980, p. 585).

Much of the previous work on the non-initial placement of PNAs in sports commentary speech is, however, not related to the speed of the sport, is not quantitative nor has it been applied to languages other than English. In the following sections of this paper we will address these shortcomings by looking at non-initial placement of PNAs in football commentary in English and Persian, and horse racing commentary in English and Japanese.

\section{Method}

\subsection{Data}

Data from football and horse racing were selected in part because both horse racing and football have a sufficient number of participants to place a load on the retrieval from long-term memory of the names of the participants, i.e. as a control on lexical retrieval. By contrast, in singles tennis there are only two players and so, not-withstanding the high speed of significant events in singles tennis, two names might well be held in working memory.

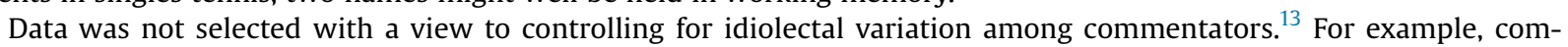
parisons might be made among play-by-play commentators of ice hockey representing a fast sport, or cricket

\footnotetext{
13 Note that the current study compares only a few individuals. Sports commentators have many personal idiosyncrasies in their commentary speech and so further research of a wider range of commentators in a variety speech communities would be necessary to support the findings of this study.
} 
commentators representing a slow sport. Nor was data selected with a view to controlling for the genrelects of sports commentary of sports with roughly the same speeds. For example basketball and football as medium-paced sports (Kuiper, 2009). ${ }^{14}$

The factor "speed of significant events to be reported" had two levels: Horse racing was selected as a fast sport, football as a medium-paced sport. Commentaries of both these were of televised sport. ${ }^{15}$ As a proxy for a slow sport, we chose written, online commentary of medium-paced sport: football (Bergh, 2011; Chovanec, 2008; Ghadessy, 1988; Jucker, 2006, 2010; PérezSabater et al., 2008).

Spoken commentaries were transcribed using the following conventions. The transcription in Table 6 for Persian, Persian being written right to left, has the Persian text and written alphabetic transcript in right to left order while the English wordfor-word gloss and idiomatic gloss are written left to right. Elsewhere in the text the examples are written from left to right for ease of reading.

The Japanese transcriptions follow the conventions of the Leipzig Glossing rules with some additions and modifications. Transcriptions are left aligned but not aligned vertically because of space. Instead, commas are used to indicate the division of phrases as in the original (in Japanese). Hepburn Romanization is used for Japanese, as opposed to Kunrei-shiki Romanization. However, a macron is not used for the long vowel, but two vowels were used instead (e.g., Tookyoo for Tōkyō). ${ }^{16}$

The English spoken football commentary data were drawn as follows. The commentary was of 45 min of televised commentary consisting of 213 coded utterances where PNAs were present, and 25 where they were not. The commentary was from the first half of the match Portugal vs. Spain in the 2010 World Cup. The commentator was Rob Hawthorne and the broadcaster Aljazeera Sport.

The Persian spoken football commentary data were drawn as follows. The commentary was of 45 min of televised commentary consisting of 95 coded utterances where PNAs were present, and 95 where they were not. The utterances were taken from the same match Portugal vs. Spain in the 2010 World Cup. The commentator was Adel Ferdosipour and the broadcaster Iran's Channel 3.

The Persian commentary was translated into a word-by-word English version for the presentation in Table 6 and analysis of the data.

Note that in football, it not being a fast sport, there is a good deal of room for colour commentary such as the following: (English) Fernando Torres who hasn't really come to life in this tournament yet ... really was misfiring in the last game. The data for analysis were selected to include only play-by-play utterances since that is the focus of our analysis. In all, the English commentary yielded about 350 utterances and the parallel Persian commentary yielded around 300 utterances including colour commentary. There is no colour commentary in horse racing commentary because the race proceeds very quickly and so there is no time for colour commentary.

The English spoken horse racing commentary data were drawn from commentary of two races from YouTube as follows:

https://www.youtube.com/watch?v=dpXOwudO9EE, (accessed 20.12.2015).

https://www.youtube.com/watch?v=v0ywOfFNhGY, (accessed 20.12.2015).

The races were the Tennoo Shoo (Emperor's prize), 5th of March 2015, commentator unknown. For this race there were 65 coded utterances with PNAs and 20 without PNAs. The second race was the Melbourne Cup, 3rd November 2015, with the commentator being Greg Miles. For this race there were 71 coded utterances where PNAs were present, and 2 where they were not.

The Japanese spoken horse racing commentary data were drawn from the commentaries of two races from You Tube as follows:

\footnotetext{
14 A genrelect consists of two aspects: (1) a social aspect relating to where the genre is used, by whom, when, etc, and (2) text type features characteristic of the genre.

15 There is evidence that radio and TV commentaries of the same game are not the same (Kuiper and Lewis, 2013).

${ }^{16}$ Abbreviations used for Japanese transcription.

ASP

COMP

COP

DAT

GEN

NOM

PAST

PLAIN.PRES

PLAIN.PAST

POL

POL-PRES

POL.NEG-PAST

PRES

SSP

Q

TOP

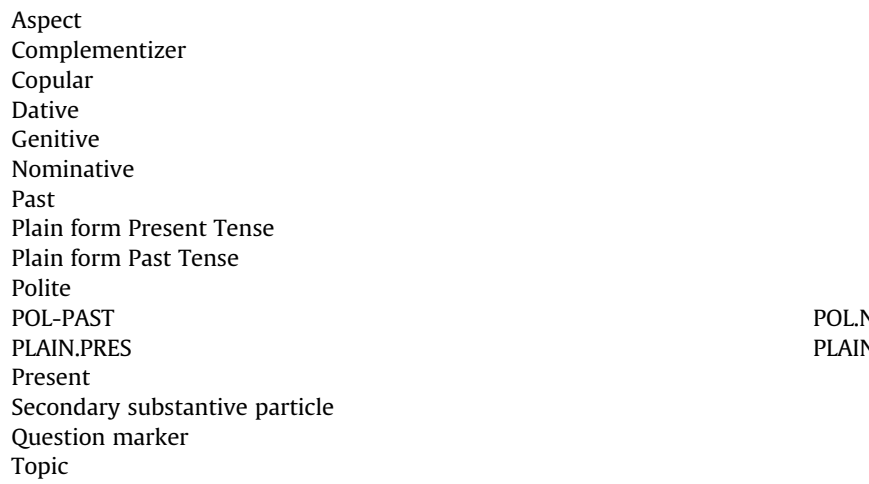


http://www.youtube.com/watch?v=kS14VpX-Uy0, (accessed 12.4.2013).

http://www.youtube.com/watch?v=V3mJwPa1 kq4, (accessed 20.4.2013).

The races were the Tennoo Shoo (Emperor's prize), 28 October 2012, with the commentator being Yooji Funayama. For this race there were 33 coded utterances where PNAs were present, and 2 where they were not. The second race was the Melbourne Cup, 7 November 2006, with the commentator being Raita Nakano. For this race there were 45 coded utterances where PNAs were present, and 15 where they were not.

The two on-line written commentaries were of the football match Liverpool vs. Chelsea 16.5.2016, https://www. theguardian.com/football/live/2016/may/11/liverpool-v-chelsea-premier-league-live, (accessed 16.5.2016) and the rugby football match Lions vs. Blues in the Super 15 Rugby competition 15.5.2016 taken from the New Zealand Herald web site http:// www.nzherald.co.nz/rugby/match.cfm?season=2016\&competition=205\&match=516127, (accessed 15/5/2016). The football match yielded 143 clauses of which 106 clauses were of play-by-play commentary while the rugby football match yielded 113 clauses of which 96 consisted of play-by-play commentary.

\subsection{Data editing conventions and analysis types}

A first analysis compared those clauses with a PNA with those without a PNA in the play-by-play in spoken sports commentaries, the objective being to show that there is a statistically significant effect of having to retrieve a PNA from memory on the non-initial placement of PNAs. The prediction for the analysis of these data is that constituents wITH a PNA will exhibit more non-initial placements of these constituents than constituents witHout a PNA.

The analysis of written on-line play-by-play commentary also compared clauses having non-PNA subjects with clauses where a PNA was present in medium-paced sports. ${ }^{17}$ For these data the prediction is that there would be no significant difference between clauses with a PNA and those without such a constituent since the time taken to write a commentary places little time pressure on the writer to retrieve the PNA from memory. ${ }^{18}$

In all the data sets, utterances consisting solely of a PNA were excluded from analysis. Also excluded were cases where the same PNA was repeated in the following clause in spoken commentary; this on the assumption that where a commentator repeats a PNA shortly after its initial recall, further recall from memory is not involved. For the effect of such repetition see Table 1 which makes clear that in all but one of the four commentary types repetition of a PNA in the following clause favours initial placement of that PNA. ${ }^{19}$

Table 1

Repetition of a PNA in following clause.

\begin{tabular}{lllll}
\hline Position of PNA & $\begin{array}{l}\text { Spoken English football } \\
\text { commentary }\end{array}$ & $\begin{array}{l}\text { Spoken Persian football } \\
\text { commentary }\end{array}$ & $\begin{array}{l}\text { Spoken English racing } \\
\text { commentary }\end{array}$ & $\begin{array}{l}\text { Spoken Japanese racing } \\
\text { commentary }\end{array}$ \\
\hline In initial position & $6(86 \%)$ & $0(0 \%)$ & $3(75 \%)$ & $7(78 \%)$ \\
In non-initial position & $1(14 \%)$ & $4(100 \%)$ & $1(25 \%)$ & $2(22 \%)$ \\
\hline
\end{tabular}

For the second analysis, which was to document different constructions for the positioning of the PNA, only the spoken data were used. Here utterances in which PNAs did not appear were excluded from analysis, for example in cases of pro drop or the pronominalization of the PNA, since in such utterances the commentator does not have to retrieve from memory the name of the player or horse since, in commentary speech, it has been retrieved in the immediately preceding utterance. Thus such utterances do not provide evidence of which syntactic means may be employed for the non-initial placement of PNAs. However, utterances in the form of small clauses or participial clauses were included since small clauses and participial clauses have subjects which can be agents or actors. As such they can be either left or right of the clause. ${ }^{20}$ For example, in (English e.g.) Ronaldo keeping a more central role, the PNA is in initial position although it is the subject of a non-finite clause. In (7) the PNA is on the right of the clause.

(7)

در سمت راست فرناندو تورس

Dær sæmte râst Fernando Torres

On the side right Fernando Torres

on the right side Fernando Torres

In (8) the PNA is in initial position.

\footnotetext{
$\overline{17}$ There is no on-line written commentary for fast sports such as horse racing.

18 Note that in spoken commentary, clause chaining is the main means of creating coherence (Halliday and Hasan, 2013; Pawley and Syder, 2000) while written commentary allows time for subordinate clauses to be produced and these are in evidence. Note that in such clauses the subject is often a pronoun (or PRO) and in the case of a tensed clause is usually preceded by a subordinating conjunction.

19 This supports our theory that not having to recall a PNA from memory favours the canonical initial placement of PNAs.

${ }^{20}$ It is not relevant to the argument of analysis 1 how many of these there might be in the data.
} 
(8)

تباكو در ميانه مي ميدان

Tiago dær miyâneye meidan

Tiago in middle of field

Tiago in midfield

\subsection{A sketch of relevant properties of Persian and Japanese syntax}

Persian and Japanese were selected as languages of interest for the examination of non-initial placement of PNAs because they are canonically verb-last.

Clauses in Persian are canonically (S)OV (Dehghani, 2002; Perry, 2005; Windfuhr, 1979), for example

(9)

كريس رونالدو حركتى رو آغاز كرده

Cris Ronaldo hærækæti ro âghâz kærde

Cris Ronaldo a move started has

Cris Ronaldo has started a move.

Adverbials, other than sentential adverbs which come clause initially, can appear anywhere pre-verbally (Dehghani, 2002, p. 22), for example,

(10)

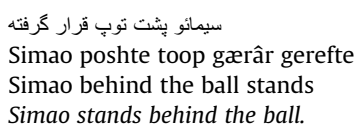

In X-bar terms, it appears that parameters for Persian are like those of German and Dutch subordinate clauses, IP is I-last and VP is V-last. Persian is also a pro-drop language which, for the purposes of the second analysis in this paper, is not relevant since we are examining the syntactic position of overt PNAs.

Persian is also variously termed a free word order language or a language which permits scrambling. While the details of the mechanisms underlying scrambling are contested, they appear in part to be explained by the leftward position of constituents being a topic or in focus position (Browning and Karimi, 1994). Dehghani (2002) supposes that all the following orders are grammatical but that the second two sound strange to native speakers of Persian: OSV, OVS, VSO, VOS. Since the canonical order is (S)OV, that only leaves SVO as ungrammatical. The identification of leftward scrambling with focus and topic suggests that subjects in non-initial positions are not in focus. Passives in colloquial Persian (which also promote patient markers leftward) normally have deleted agents. General omission of the copula verb is not permitted in Persian (Toosarvandanim, 2008). Adjectives come after their head nouns in Persian.

'Japanese is considered rigidly "head final": its basic word order is SOV (Kuno, 1978). It is also a pro-drop language, and both null subjects and null objects are possible.' (Koike, 1997, p. 181). Japanese marks its arguments with particles, the significant ones for commentary speech are -wa usually taken to be a topic or theme marker of new information and -ga which is taken to mark old information and nominative case. In spoken Japanese particles are often omitted (Siegel, 1999).

\subsection{Data coding}

To test the main hypothesis, all transcripts of spoken and written commentary were coded so as (1) to distinguish between those clauses in which a PNA was present and those where such a constituent was not present; (2) to check how frequently the subject containing the PNA was in clause-initial position compared to clauses where the subject did not contain a PNA, the aim being to see if the necessity to recall a PNA from memory resulted in significant non-initial placement of PNAs; and (3) to check, in the presence of clear cases of formulae, whether such formulae had slots for the PNA in non-initial or initial position. This third coding was only possible for the English commentaries since the first author was familiar with these commentary types and could thus identify the genre-specific formulae by introspection, while the native speakers of Japanese and Persian were not sufficiently familiar with commentary traditions in their languages to make a similar determination as to the formulaic status of constituents. ${ }^{21}$

To test the consequential hypothesis falsifying a strong functional analysis of non-initial placement of PNAs, commentary clauses were coded as follows:

a. Was PNA in initial position in the clause?

b. Was the PNA in initial position pre-modified?

c. Was the PNA in an oblique argument position, e.g. PNA in a passive? Also included here were cases in the Persian commentary where the PNA is in a prepositional possessive, e.g.

\footnotetext{
${ }^{21}$ We have been unsuccessful in searching, in our business networks, for Japanese an Persian linguists with sufficient background knowledge, time, and interest. We hope that our paper may stimulate interest in this kind of data.
} 
(11)

تكل بلند راموس

Tækle bolænde Ramos

Tackle high of Ramos

High tackle of Ramos.

We take such cases to be an oblique argument of a PNA within NPs after Chomsky (1970).

d. Was there a coordinating conjunction in initial position in the clause?

e. Was there an adverbial in initial position in the clause?

f. For Persian and Japanese, did the PNA appear post-verbally?

g. For Japanese, was the PNA inflected?

h. For English, was there evidence of postposition of PNAs around verbs by inversion?

\section{Results}

\subsection{Overview of analysed data}

The total corpus yielded 1160 of coded utterances. After editing out the data which were not relevant to this research, 822 clauses remained for analysis. Of these, 590 exemplars included PNAs (see Table 2). In line with our expectations, the 2/3 majority of SPOKEN clauses manifest these PNAs in non-clause-initial position, whereas in the wRITTEN (blog) commentaries (rightmost column), 2/3 of the PNAs occur clause-initially. This means that the data set subject to analysis is in line with the basic prediction from memory retrieval of PNAs under time pressure. ${ }^{22}$

\subsection{The clause-initial vs. non-clause-initial position of constituents with and without PNAs}

Here we compared clauses for the production of which commentators must identify the agent in the visual field and then recall a PNA, with clauses in which there are no PNAs. Table 2 shows the numbers of such clauses in our corpus. Each of the five $2 * 2$ contingency tables represents an association between presence/absence of a PNA and (non-)clause-initial placement of the constituent containing that PNA. Our theory predicts that the numbers in the cells on the North-West to South-East diagonal should be higher than those on the SW-NE diagonal. This pattern is manifested by the first two contingency tables in Table 2, but not by any of the three other ones (nor by the underlying data sets of the individual commentators).

Table 2

The effect of the presence of a PNA on its placement in clauses. ${ }^{23}$

\begin{tabular}{lll}
\hline Language and type of commentary & Clauses without PNA & Clauses with PNA \\
\hline English spoken football commentary & & 68 \\
Subject clause-initial & 24 & 139 \\
Subject non-clause-initial & 18 & \\
Persian spoken football commentary & $\chi^{2}=8.84, p<.005$ (sign.) & 30 \\
Subject clause-initial & 70 & 62 \\
Subject non-clause-initial & 27 & \\
English spoken racing commentary & $\chi^{2}=29.65, p<.001$ (sign.) & 41 \\
Subject clause-initial & 9 & 91 \\
Subject non-clause-initial & 12 & 15 \\
Japanese spoken racing commentary & $\chi^{2}=1.15, p=.284$ (not sign.) & 55 \\
Subject clause-initial & 6 & 66 \\
Subject non-clause-initial & 11 & 23 \\
English written football commentary & $\chi^{2}=1.44, p=.231$ (not sign.) & \\
Subject clause-initial & 26 & \\
Subject non-clause-initial & 29 & \\
& $\chi^{2}=10.65, p<.005$ (sign.) & \\
\hline
\end{tabular}

Note that the fifth data set includes only main clauses since the other four data sets are virtually all main clauses. Furthermore the data in the fifth data set comprise $79 \%$ of all the clauses in the written commentary data.

\footnotetext{
22 An anonymous reviewer asks how big is big enough? Our response is that there is no corpus big enough to provide certainty for any theory. However we are satisfied that the data set we have assembled enables us to provide evidence (and thus make findings) on the standard of balance of probabilities. We predict, given how stereotypical much sports commentary of medium- and fast-paced sports is, that more data would be rather like the data we have assembled. We would, of course welcome others to assemble other and larger data sets along the same lines as ours.

23 The data patterns obtained from the individual commentators agreed with the combined patterns in terms of significance levels: significant for each of the English spoken racing commentators, but not significant for the individual English spoken football commentators ( $p$-values calculated with Fisher's Exact Test).
} 
That the data patterns for spoken and written football commentary diverge is unsurprising, as argued above. (As for the fifth $2^{*} 2$ table, dealing with written football commentary: This pattern is statistically significant, but in the direction opposite to the prediction (with the higher numbers populating the SW-NE diagonal.) However, the contrast between spoken football vs. spoken racing commentary is not predicted from the theory. Our analysis shows instead that, under time pressure, race callers move most subjects to the right. Since most of the clauses have PNA subjects and the paper proposes a hypothesis why this should take place, it then also suggests that syntactic priming under serious time pressure would lead to almost all clauses having a rightward subject since the PNA subjects are almost all in a rightward position. See below. ${ }^{24}$

In the next subsection we present data on the use of formulae. These data suggest the possibility that time pressure facilitates the activation of formulae that allow non-clause-initial placement of PNAs.

\subsection{Formulae with clause-initial and non-clause-initial subjects}

We may attribute the difference between football and racing commentary to the speed of the action with which the commentator must keep pace, and the speed of the commentary itself as we saw above by the fact that racing commentators produce clauses at twice the rate of football commentators. Football is a medium-paced sport in the terms mentioned in Section 2 whereas horse racing is a fast sport. So in producing horse racing commentary the commentator relies on non-initial placement in most clauses, using fronted adverbials and coordination in initial position. This is not as necessary in football commentary.

However, the question which remains is why horse racing commentators do not place subjects in initial position when no memory retrieval of a PNA is required. We have three plausible explanations. The first is that the high frequency of non-initial placements of PNAs acts as a form of syntactic priming creating a bias toward non-initial placement of nonPNA subjects (Bock, 1986). ${ }^{25}$ In this paper, we will not pursue this type of explanation because it requires detailed data on temporal intervals between utterances and on the ordering of utterances; such a study is beyond the scope of the present paper.

The second is that the extremely high time pressure imposed in race caller, leads the callers to use a very high proportion of non-clause-initial subjects. See Table 3. The proportion of non-clause-initial subjects in horse race calling is significantly higher than in football commentary, suggesting a ceiling effect (in race calling). Taking recourse to constructions with nonclause-initial subjects may be a general "strategy", exercised and skillfully applied by professional race callers, that benefits clauses with and without PNAs.

Table 3

Clause-initial vs. non-clause-initial position of Subject NPs in spoken commentary of a medium-paced (football) and a fast (horse racing) sport. The proportion of non-clause-initial Subjects is significantly higher in the fast-than in the medium-paced sport (68\% vs. $42 \%) ; \chi^{2}=13.26, p<.001$.

\begin{tabular}{lll}
\hline Position of Subject (with or without PNA) & Spoken football commentary (English + Persian) & Spoken racing commentary (English + Japanese) \\
\hline Clause-initial & 192 & 71 \\
Non-clause-initial & 246 & 169 \\
\hline
\end{tabular}

The third explanation, to be explored here, is that most formulae used by race callers have slots for trailing PNAs. ${ }^{26}$ We would expect formulae to be prevalent in the speech of sports commentators given the necessity for the commentator to be fluent, fluency being facilitated by the use of formulae (Pawley and Syder, 1983; Sprenger et al., 2016). ${ }^{27}$ Most horse racing formulae have the PNA in a non-clause-initial position, as do many football formulae. This can be accounted for by the assumption that ' $(\mathrm{h})$ aving a stock collection of forms which allow naming the agent to be deferred must ease the sportscaster's encoding task considerably.' (Green, 1980, p. 586). Wasow (1997) makes a similar case for one formula, and

\footnotetext{
${ }^{24}$ The difference may have to be sought in the contrast between commentary on agents in the case of football players and actors in the case of race horses. It seems however that there is no clear difference in the data we have collected between recalling the names of agents or actors. Both tend to move rightward under time pressure. We suggest for further research into the possibility that there is a difference between agents and actors, e.g., a study of commentary on field hockey and greyhound racing.

${ }^{25}$ For a recent overview of numerous priming studies, see Mahowald et al. (2016) and Branigan and Pickering (in press). Strictly speaking, evidence for syntactic priming requires searching, in the data set, for pairs of consecutive sentences with PNA and non-PNA subjects, with these subjects in identical or non-identical positions: (1) both PNA, in identical positions; (2) both PNA, in different positions; (3) both non-PNA, in identical positions; (4) both non-PNA, in different positions; (5) one PNA, the other one non-PNA, in identical positions; (6) one PNA, the other one non-PNA, in different positions; and then testing whether identity of (non-)PNA status promotes the likelihood of identical position. In the case of our data, there are insufficient cases to perform such a procedure. It is a possibility for further research.

${ }^{26}$ Formulae form a subset of the clauses used in commentary speech. Slots are empty argument positions in formulae which are otherwise lexically specified. Their identification is dealt with earlier.

${ }^{27}$ The prediction is that this finding will replicate for Japanese race calling.
} 
attributes the non-initial position of the PNA in that formula to having to look up the name of a baseball player on a scorecard which acts as an auxiliary memory (Newell and Simon, 1972). Race callers, however, cannot consult their racebook since they are following the race, moment by moment, through field glasses.

We would therefore predict that oral commentary of football matches and horse racing shows a preference for formulae containing a non-initial slot for the placement of PNAs in contrast to those not having a PNA slot. In written (blog) commentary, formulae would not show such a contrasting preference since there is no processing factor tending to delay PNA retrieval. Hence most of the formulae of the written blog commentary have the subject in initial position. These preferences are illustrated in Table $4 .^{28}$

Table 4

The location of slots in formulae. Due to the very small numbers in some cells, we used Fisher's Exact Test instead of $\chi^{2}$.

\begin{tabular}{llc}
\hline Language and type of commentary & Clauses without PNA & Clauses with PNA \\
\hline English spoken football commentary & & 14 \\
Subject clause-initial & 13 & 85 \\
Subject non-clause-initial & 0 & \\
& Fisher's Exact Test: $p<.001$ (sign.) & 49 \\
English spoken racing commentary & 12 & 66 \\
Subject clause-initial & 0 & \\
Subject non-clause-initial & Fisher's Exact Test: $p<.001$ (sign.) & \\
& 28 & 57 \\
English on-line written commentary (numbers of clauses including subordinate clauses) & 3 \\
Subject clause-initial & 1 & \\
Subject non-clause-initial & Fisher's Exact Test: $p=1$ (not sign.) & \\
&
\end{tabular}

Our data support our hypothesis that there is a significant difference between formulae containing a PNA slot and those which do not have such a slot in the case of spoken commentary but not the written commentary: compare the first and the last data set in Table 4. We attribute this difference to the differing time pressure conditions of the lexical memory retrieval of PNAs during speaking and writing. ${ }^{29}$

\subsection{Analysis of positional variants of clauses containing a PNA}

We now compare the processing theory we have just found general support for with the communicative theory that placement of PNAs is determined by communicative functional considerations. The data on which this comparison is based follow.

Examples of utterances in the English football commentary exemplifying each positional possibility are to be found in Table 5.

Table 5

English spoken football constructions showing placement of PNA.

\begin{tabular}{|c|c|c|}
\hline Construction & Examples & Number of observed cases \\
\hline PNA in initial position in the clause & Ramos away & 68 \\
\hline PNA in initial position pre-modified & (No cases) & 0 \\
\hline PNA in an oblique position & Played off by Almeida & 42 \\
\hline Coordinating conjunction in initial position & And now Xavi & 18 \\
\hline Adverbial in initial position & From the block Almeida unable to break & 89 \\
\hline
\end{tabular}

Note that most of the fronted adverbials were from one of two formulae, the first of which inverts PNA order around be:

Here/there/it is PNA (29\%), Now PNA (11\%).

Examples of utterances exemplifying each positional possibility in the Persian football commentary are to be found in Table 6.

\footnotetext{
28 The clauses surveyed in Table 4 are found in the formulae found in our data set.

29 An anonymous reviewer has suggested that bloggers (like colour commentators) perform a summarizing function which could lead to a difference in the formulae they use. While that is the case, the reason bloggers can summarize is that they (like colour commentators) have the time to do so.
} 
Table 6

Persian spoken football constructions showing placement of PNA.

\begin{tabular}{|c|c|c|}
\hline Construction & Examples & Number of observed cases \\
\hline $\begin{array}{l}\text { PNA in initial position in } \\
\text { the clause }\end{array}$ & 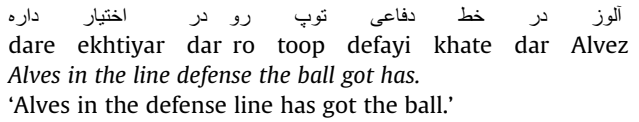 & 30 \\
\hline PNA in initial position pre-modified & 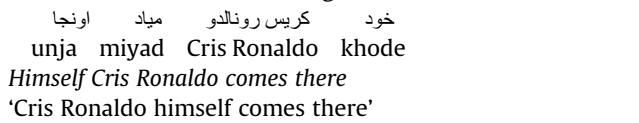 & 2 \\
\hline PNA in an oblique position & 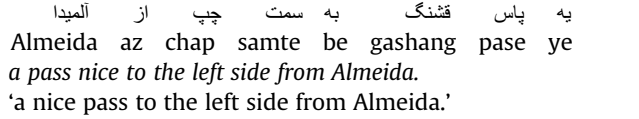 & 17 \\
\hline Coordinating conjunction in initial position & 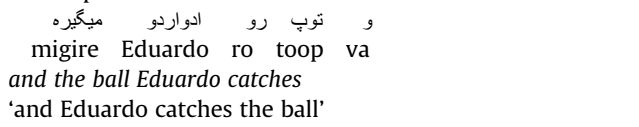 & 15 \\
\hline Adverbial in initial position & 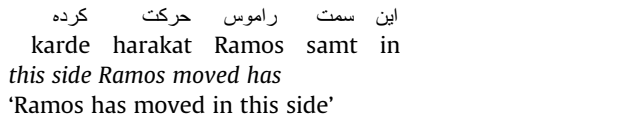 & 21 \\
\hline PNA appears post-verbally & 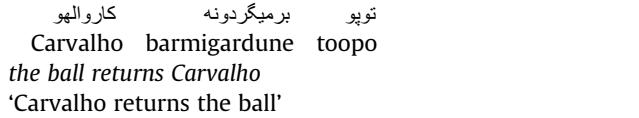 & 22 \\
\hline
\end{tabular}

Note that almost a quarter of the PNAs appear to the right of the verb.

Examples of utterances exemplifying each possibility provided in the English racing commentaries are to be found in Table 7.

Table 7

English spoken racing constructions showing placement of PNA.

\begin{tabular}{lll}
\hline Construction & Examples & Number of observed cases \\
\hline PNA in initial position in the clause & Trip to Paris jumped well. & 41 \\
PNA in initial position pre-modified & (No cases) & 0 \\
PNA in an oblique position & They're being followed then by Preferment at the end of the field & 21 \\
Coordinating conjunction in initial position & And Bondi Beach off the track is making ground too & 25 \\
Adverbial in initial position & Out wide three wide Admire Deus starts to go on & 21 \\
Post-posing of PNA around verb & Running on is Sounds of Earth & 34 \\
\hline
\end{tabular}

Examples of utterances exemplifying each possibility provided in the Japanese racing commentaries are to be found in Table 8.

Table 8

Japanese spoken racing constructions showing placement of PNA.

\begin{tabular}{|c|c|c|}
\hline Construction & Examples & $\begin{array}{l}\text { Number of } \\
\text { observed } \\
\text { cases }\end{array}$ \\
\hline $\begin{array}{l}\text { PNA in initial } \\
\text { position } \\
\text { in the clause }\end{array}$ & $\begin{array}{l}\text { イエーツが早めに、二番手から前を追っていきました。 } \\
\text { Ieetsu-ga hayame-ni, ni-bante-kara mae-o ot-te-iki-mashi-ta. } \\
\text { Yeats-NOM at this early stage, second position-from the lead-ACC chase-COM go-POL-PAST } \\
\text { Yeats is chasing the lead from second at this early stage. }\end{array}$ & 15 \\
\hline $\begin{array}{l}\text { PNA in initial } \\
\text { position } \\
\text { pre-modified }\end{array}$ & $\begin{array}{l}\text { 番ダイワファルコン、3 番手で向こう正面に入りました。 } \\
\text { Kyuu-ban Daiwfarukon, san-bante-de mukoo joomen-ni hairi-mashi-ta. } \\
\text { Number nine Daiwa Falcon, the third position-in opposite homestretch-to enter-POL-PAST } \\
\text { Number nine, Daiwa Falcon, in the third position, entering the opposite homestretch. }\end{array}$ & 22 \\
\hline $\begin{array}{l}\text { PNA in an oblique } \\
\text { position }\end{array}$ & $\begin{array}{l}\text { その外から、どうやらザビートが行くのか。 } \\
\text { Sono soto-kara, dooyara Zabiito-ga ik-u-no ka. } \\
\text { Its outside-from, somehow Zabeat-ACC go-PLAIN.PRES-SSP Q } \\
\text { From its outside, somehow, is Zabeat going? }\end{array}$ & 1 \\
\hline $\begin{array}{l}\text { Co-ordinating } \\
\text { conjunction } \\
\text { in initial position }\end{array}$ & $\begin{array}{l}\text { そして、ズィッピングミ番手、その外からイエーツ、キアラン・ファロン、上がっていきました。 } \\
\text { Soshite, Zuippinngu san-bante, sono soto-kara Ieetsu, Kiaran Faron, agat-te-iki-mashi-ta. } \\
\text { And, Zipping the third position, its outside-from Yeats, Kieren Fallon, come-COM go up-POL-PAST } \\
\text { And, Zipping in third, from its outside, Yeats, Kieren Fallon, coming up. }\end{array}$ & 8 \\
\hline $\begin{array}{l}\text { Adverbial in initial } \\
\text { position }\end{array}$ & $\begin{array}{l}\text { まず注目通り } 2 \text { 番のシルポートが先手を取ります。 } \\
\text { Mazu chuumokudoori ni-ban-no Shirupooto-ga sente-o tori-mas-u. } \\
\text { First of all, as expected number two-GEN Silport-NOM a lead-ACC take-POL-PRES } \\
\text { First of all, as expected, number two Silport has taken the lead. }\end{array}$ & 39 \\
\hline
\end{tabular}


Table 8 (continued)

\begin{tabular}{|c|c|c|}
\hline Construction & Examples & $\begin{array}{l}\text { Number of } \\
\text { observed } \\
\text { cases }\end{array}$ \\
\hline $\begin{array}{l}\text { PNA appears post } \\
\text { verbally }\end{array}$ & $\begin{array}{l}\text { 素晴らしいスタートからいったんは先頭のシーンがありましたが、さあ、逃げるのか、控えるのか、、、デルタブルー } \\
\text { ス。Subarashii sutaato-kara ittan-wa sentoo-no shiin-ga arimashi-ta ga, saa, nige-ru-no-ka, hikae-ru-no-ka, } \\
\text { Derutaburuusu. } \\
\text { Wonderful start-from once-TOP lead-GEN scene-NOM exist-POL-PAST-but, well, run-PLAIN.PRES-SSP Q hold-PLAIN. } \\
\text { PRES-SSP Q Delta Blues } \\
\text { After the wonderful start, once the leader in the race, well, taking first, or holding its position, Delta Blues }\end{array}$ & 6 \\
\hline PNA uninflected & $\begin{array}{l}\text { そして、ズィッピング三番手、その外からイエーツ、キアラン・ファロン、上がっていきました。 } \\
\text { Soshite, Zuippinngu san-bante, sono soto-kara Ieetsu, Kiaran Faron, agat-te-iki-mashi-ta. } \\
\text { And, Zipping the third position, its outside-from Yeats, Kieren Fallon, come-COM go up-POL-PAST } \\
\text { 'And, Zipping in third, from its outside, Yeats, Kieren Fallon, coming up.' }\end{array}$ & 48 \\
\hline
\end{tabular}

Note that all cases of pre-modification in Table 8 are by one of the two race callers and all consist of the formula "number X, PNA". Note too that only $33 \%$ of Japanese PNAs are inflected.

It seems from the data above that the majority of the clauses in all the commentaries have ways of locating the PNA to the right of the extreme left periphery of the clause. In many cases this is to place the PNA away from its canonical position. More than 50\% of clauses in all commentaries have such locations for the PNA. In Japanese and particularly in Persian, the PNA is sometimes located post-verbally. The syntactic means by which this is accomplished tend also to have similar distributions with the fronting of adverbials commonly serving that purpose and preposing around be very common in English race calling. As suggested above, much of this positional work in race calling is done by formulae which have an empty position, a slot, in non-initial position for the PNA. A comparison of the ways in which the various commentary types use the available syntactic placements for PNAs can be found in Table 9.

Table 9

Preferences for placement of PNAs in spoken commentary. The numbers are percentages of the total number of coded utterances. They do not add up to 100 because an utterance may feature several properties simultaneously.

\begin{tabular}{|c|c|c|c|c|c|c|c|c|c|}
\hline & $\begin{array}{l}\text { PNA } \\
\text { initial }\end{array}$ & $\begin{array}{l}\text { Pre-modified } \\
\text { PNA }\end{array}$ & $\begin{array}{l}\text { PNA } \\
\text { oblique }\end{array}$ & $\begin{array}{l}\text { Initial } \\
\text { coordinator }\end{array}$ & $\begin{array}{l}\text { Fronted } \\
\text { adverbial }\end{array}$ & $\begin{array}{l}\text { PNA } \\
\text { postverbal }\end{array}$ & $\begin{array}{l}\text { Inflected } \\
\text { PNA }\end{array}$ & $\begin{array}{l}\text { It's } \\
\text { PNA }\end{array}$ & $\begin{array}{l}\text { Now } \\
\text { PNA }\end{array}$ \\
\hline English football & 33 & 0 & 20 & 8 & 41 & 43 & & 29 & 11 \\
\hline Persian football & 33 & 2 & 18 & 16 & 23 & 24 & & & \\
\hline English racing & 31 & 0 & 16 & 19 & 16 & 26 & & 3 & \\
\hline Japanese racing & 21 & 31 & 1 & 11 & 56 & 9 & 31 & & \\
\hline
\end{tabular}

\section{Functional analysis of the results}

\subsection{Propositional content}

The non-initial placement of PNA has little formal semantic reflex. Fronted adverbials may have different scope to their scope in clause final position. Preposing around be and other verbs leaves a proposition that, in terms of its truth conditions, is no different from a PNA in initial position. So a functional analysis of the propositional content of a commentary clause needs to explain why a football commentator would say 'Here is PNA' rather than 'PNA is here.' What is its communicative point? The television viewer in the case of football has the camera following the ball. The player on the ball is manifest. The fact that such a player is 'here' is manifest. Only 'here' is used, so a player cannot be anywhere else but 'here'. It appears that the use of this formula is just a short clausal way of saying that the player currently 'on the ball' being followed by the camera is named $\mathrm{X}$. Functionally the fact that the player is in clause-final position is a result of the formula having a slot for the player's name in final position. Perhaps here is in focus and is given information, and the player's name is new information or maybe it is just a useful formula for getting the player's name two syllables to the right of the beginning of the utterance.

In the case of the NPs in Persian commentary with the PNA in oblique position, there is no semantic difference between these and an equivalent small clause, e.g. compare (12) and (13).

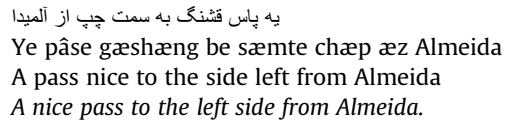




\subsection{Pragmatics}

If pragmatics is seen as involving the processes for the recovery by the hearer of the speaker's communicative intent on the basis of what has been said and the contextual assumptions of the parties to the discourse, then for most commentators and their audience the contextual assumptions will be closely aligned. Why listen to a commentary otherwise? Hearer inferencing in commentary speech perception is based on sport-specific shared vocabulary and sports-specific contextual assumptions, e.g. English Xabi picking up Fernando Torres. Such an utterance is probably not contextually disambiguated by the immediate context but by the wider context of this being a football commentary. To pick up in football means 'to pass successfully to'. Using the formula Here is PNA again as an example, hearers who are familiar with sports commentary know that, in the context of football commentary, Here is PNA is intended to mean, 'the player now "on" the ball is PNA'. Pragmatic disambiguation takes place on the basis of the contextual assumption that the specific meaning of the expression restricted to football is intended and not that one player is literally picking another up.

\subsection{Thematic structure}

There are no cases of themes as in a Dik functional analysis, i.e. cases like As for Puscas, he passes the ball to Di Stefano. All initial constituents are themes in a Hallidayan analysis of the clause as message. Themes, in the case where the PNA is not the theme, i.e. marked themes, include adverbials, verb phrases (predicator plus complement and/or adverbial in Hallidayan terms), intensive complements (in Hallidayan terms), extensive complements (in Hallidayan terms), coordinators. There seems to be no coherent explanation for the initial placement of these constituents in communicative terms. When one looks at the local context, such marked themes seem to be unmotivated from a communicative viewpoint.

\subsection{Discourse functions: given and new information}

In a discourse functional analysis, new information is expected to come later in a clause while the given information comes first. That is the case in about $70 \%$ of cases but not all would be predicted by a strong functional theory. We have seen that in about $30 \%$ of cases in all six commentary texts in the spoken sports commentary corpus, the PNA comes utterance-initially. That cannot be because it is given information since the name of the player or horse is new information. That is why the commentator names the player or horse. In play-by-play commentary, given information is rare since there is no point in communicating it. That is why the ball is seldom explicitly mentioned in basketball and football commentary. Commentators communicate what is assumed not to be given. Generally, if there had been some given information it would normally have been mentioned in initial position. In the other cases, one would have to suppose that the adverbials, formulaic chunks like here is PNA and now PNA might be considered given information. In some very obvious way they are, but only as clichés, not as discourse driven.

\subsection{Topic and comment}

Mackenzie and Keizer suggest that there is no topic function in English (Mackenzie and Keizer, 1991). Persian has no formal topic marking. Only Japanese has formal topic (theme) marking with the suffix (particle) -wa. Constituents with topic marking include the following:

$\begin{array}{ll}\text { PNA } & 4 \text { cases } \\ \text { Fronted adverbial } & 9 \text { cases } \\ \text { Other fronted NPs such as leading bunch } & 5 \text { cases }\end{array}$

Marking the PNA as topic is understandable given that it is a topic but not if it is taken to be given (old) information. To reiterate, the horse named by a race caller is new information. That is why the commentator mentions it. It may be that all fronted constituents are marked as topics formally but functionally a fronted adverbial is not a topic. Also, topics are sometimes suggested to be given information but since there is almost no given information in a play-by-play commentary, that does not aid a functional explanation.

\subsection{Problems with functional explanations for PNA placements}

A strong functional account for these different syntactic configurations for the placement of PNAs needs different explanations for each placement. For example, if a PNA is new information, then it should be placed later in the clause as it is in about seventy percent of cases. But about thirty per cent of PNAs are placed in initial position in all three languages. It is hard to make a case for PNAs as sometimes being new and sometimes given information particularly since, for the first analysis, we have deleted all cases of pro drop where the subject has been mentioned previously and is therefore given information.

A strong functional account would also need an explanation for the occasional use of a coordinating conjunction. Why use them at all? It is conceivable that a narrative like a commentary might have coordinating conjunctions throughout or have none at all, as some of the commentary data show. If one looks at the commentary as a whole and asks why is there a coordinating conjunction at the beginning of some clauses but not others, it is difficult to see a communicative purpose for the difference. 
Halliday (1985) claims that the functional difference between preposing around be and a non-preposed form is a difference in which constituent is the theme. Thus there should be a discourse functional difference between on the right is Ronaldo and Ronaldo is on the right. It is difficult to see what that difference might be. The same is true for fronted adverbials. As such they are in topic or theme position. There does not seem to be a compelling reason why this should be so. Again in the Japanese race call,

(14)

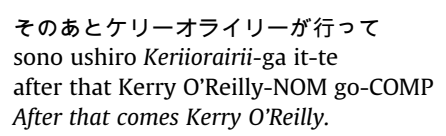

does not seem communicatively different from

(15)

Kerry O'Reilly-NOM after that go-COMP.

Kerry O'Reilly comes after that

The same argument can be mounted for the postverbal placement of PNAs in Persian football commentary. Such placement of a PNA seems to have no communicative purpose. Since this placement is syntactically relatively ill-formed, it is difficult to attribute the placement to a communicative motivation. For example

(16)

اما ايستادگى كرد يويول

æmma istâdegi kærd Puyol

But resisted Puyol

But Puyol resisted.

In most clauses in the commentaries we have analyzed there is either no or one and only one device for non-initial placement of PNA per clause. From a communicative point of view, there seems no reason why a clause should not have both an initial coordinator and a fronted adverbial and, in Persian, postverbal placement of the PNA. But such instances are rare. Table 10 shows the number of instances of non-initial placement constructions in each of the commentaries.

\section{Table 10}

Percentages of the number of syntactic configurations facilitating non-initial placement of PNAs.

\begin{tabular}{lllll}
\hline Language and sport & Number of configurations & & 2 & \\
\cline { 2 - 5 } Language and sport & 0 & 1 & $3 \%$ & \\
\hline English football & $32 \%$ & $64 \%$ & $16 \%$ & \\
$\mathrm{~N}=207$ & $33 \%$ & $51 \%$ & $11 \%$ & \\
$\begin{array}{l}\text { Persian football } \\
\mathrm{N}=92\end{array}$ & $31 \%$ & $58 \%$ & $24 \%$ & \\
$\begin{array}{l}\text { English racing } \\
\mathrm{N}=132\end{array}$ & $23 \%$ & $49 \%$ & & $3 \%$ \\
Japanese racing & & & & \\
$\mathrm{N}=70$ & & & \\
\hline
\end{tabular}

\section{A processing analysis}

Green (1980) explains the use of syntactic constructions that delay retrieval of PNAs, in terms of processing: commentators need time to retrieve the PNA from memory and thus any way of delaying the production of the PNA can offset this time course penalty in lexical retrieval. It explains the majority of clauses having none or only one device for delaying the naming of the PNA, namely once the speaker has cribbed a few milliseconds from one delaying technique, then the PNA has been accessed and can be uttered, as shown in Table 10 . Too many delaying tactics and the commentary has the potential to get behind the rate of play.

Speech processing pressure also explains clustering, which we take to be the outcome of retrieval facilitation obtained from lexical or syntactic priming. Often in a commentary a play-by-play commentator will use one formula or structural configuration for a short period of say three or four clauses and then switch to another, e.g. (English examples Here's Busquet .... and now Xavi ... now Pique ... here's Xavi ... here's Capdevila ... now Torres ... getting away from Costa ... here's Coentrao ... The explanation is that under processing pressure, repetition of the same delaying technique (or formula) for retrieving the PNA again facilitates retrieval. ${ }^{30}$

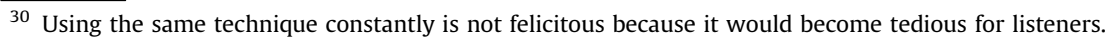


A processing explanation also explains a feature of the two commentaries of Japanese horse races. In the Emperor's Prize the racing number of each horse is large and visible on the saddle blanket of each horse. Yet one Japanese commentator tells the television audience what they can see for themselves, namely the running number of each horse before the name of the horse is said. Saying the horse's running number delays by a few milliseconds the naming of the horse which is not manifest in the visual field but must be retrieved from memory. However in the Melbourne Cup horses do not have large numbers on their saddle blankets to refer to. So the Japanese commentator of the Melbourne Cup uses fronted adverbials whose denotation is, like the saddle blanket numbers, manifest in the visual field. The English commentator of the Emperor's Prize also does not use the numerical pre-modification strategy-probably because he is experienced in racing domains where numbered saddle blankets are not used. ${ }^{31}$

The final problem for a functional analysis is that the analysis of clauses without a PNA outlined in Section 4 shows that there are significant differences in the frequency of the initial placement in clauses of subjects which are PNAs and those which are not. It is an open question how a functional analysis would explain these differences. A processing explanation, however, explains these differences simply as having to do with delaying the accessing of a PNA to gain processing time whereas when recall of a PNA is not required, speech processing does not need to delay the placement of a subject.

\section{Processing and function}

We have suggested that processing pressures in the case of sports commentary may override a communicative functional analysis of the non-initial placement of PNA. But that is not to say that there are not utterances where the function of such a placement is working in concert with processing requirements. When $70 \%$ of PNAs are in a non-initial location in the clause and such a position is a one occupied commonly by new information and the PNA is new information, then communicative function and processing are acting in concert. There are also cases where fronted adverbials play a functional role. In (English e.g.) from the block Almeida unable to break, the adverbial can be seen to be in focus position as well as allowing the PNA to be to the right of the adverbial. A functional analysis can also be made for some passives. In (English) he's been blocked there by Raul Meireles. The pronoun subject is old information and the player doing the blocking is new information. So what does one do with a situation where the facts follow from both a communicative functional analysis and a speech production analysis? One has to look at which of the two analyses deals with facts beyond these cases. Here the processing analysis covers more of the empirical ground.

In our analysis of one aspect of sports commentary, namely the non-initial positioning of PNAs, we have shown that processing pressures explain a set of syntactic processes which all have the same result, giving the speaker more time to retrieve PNAs from memory. Of course the speaker's need to communicate is also met since no one turns off the audio on TV because commentators become incomprehensible.

\section{Conclusion}

We have made a case for supposing that in sports commentary of faster sports, processing necessities can win out over communicative functional desiderata. To quote Green again, 'I have seen nothing so far that suggests that the inversions [in sports commentary speech] are capable of serving any function not served by their uninverted counterparts' (Green, 1980, p. 583). The way out of this problem for a functional analysis is to designate all psycholinguistic constraints on speech production, perception and presumably acquisition as functional, as Mackenzie (2005) does. Mackenzie proposes that the processes of speech production and the grammar of a language are separate but speech processing can 'consult' the grammar. The question then is just how this interaction takes place and what effects it has. Mackenzie uses football commentary to show that, as processing pressures increase, simplifications of syntactic structure are utilized to offset the greater time pressures created by the demands of real time speech production. Times when pressure is reduced allow for more complex syntactic structures to be utilized whereas high-pressure periods have more simple structures such as single words and phrases operating as utterances. Mackenzie also analyses examples to show how, within the limitations imposed by processing pressures, speakers' communicative ends can be achieved.

That then creates a functional theory in which everything to do with language is functional. Such a theory is difficult to test since, if the theory is general enough, one can find a functional explanation for everything and the theory is thus unfalsifiable. What can be done is to separate the processing constraints from the communicative functional requirements of speech and to allocate various linguistic reflexes to each depending on the contextual constraints operating on the speaker. We have shown that in the spoken commentary of fast- and medium-paced sports non-initial placement of PNAs is likely due to processing constraints which often win out over communicative functional requirements.

In sum, our findings are, on the balance of probabilities, that processing constraints play a significant role in syntactic encoding when speakers are under processing pressure. The rightward placement of PNAs is one consequence of such pressures as is the use of formulae with rightward located slots for PNAs. Such pressures are clearly not restricted to commentary situations but occur in many other situations. In commentary speech, the pressures are externally driven since the

\footnotetext{
31 English-speaking racing commentators are often 'imported' from English-speaking countries to call races on racetracks in locations such as Hong Kong and Japan.
} 
events to be relayed in real-time occur in the speaker's visual field. We would predict such placement to occur in any genre where the recall of PNAs from a largish population of proper nouns is necessary.

We would also predict with respect to sports commentary in Dutch and German, that in main clauses, which require to have the tensed verb in second position but first position is not canonical for subjects, adverbials would be frequent in first position, implying that the PNA would follow the tensed verb. Again we would predict that this would happen more often in racing commentary than in football commentary.

Our predictions could also be experimentally tested in a virtual reality laboratory by using as experimental subjects commentators of greater or lesser experience reporting games or races with players or horses that are more or less familiar, and then seeing how the increased pressure (by speeding up the game or race) or lack of familiarity with the events or PNAs to be reported creates more or fewer rightward placement of PNAs.

The more general consequence of our findings is that all functionalist theories of syntactic encoding need to be aware that there may and perhaps must also always be processing considerations involved and so, since we have shown that these are influenced by specific exigencies bearing on particular speakers, functional theories must account for the way in which speakers balance their processing and communicative tasks.

\section{Acknowledgements}

We are grateful to the following for useful review and suggestions regarding earlier versions: two anonymous Language Sciences reviewers, Georgia Green, Peter Hagoort and Lachlan Mackenzie.

\section{References}

Ackema, P., Neeleman, A., 2002. Effects of short-term storage in processing rightward movement. In: Nooteboom, S., Weerman, F., Wijnen, F. (Eds.), Storage and Computation in the Language Faculty. Kluwer, Dordrecht, pp. 219-256.

Bergh, G., 2011. Football is war: a case study of minute-by-minute football commentary. Rev. Veredas 15 (2), $83-93$.

Bock, J.K., 1986. Syntactic persistence in language production. Cogn. Psychol. 18 (3), 355-387.

Bock, J.K., Warren, R.K., 1985. Conceptual accessibility and syntactic structure in sentence formulation. Cognition $21,47-67$.

Branigan, H., Pickering, M., 2017. An experimental approach to linguistic representation. Behav. Brain Sci. (in press).

Browning, M., Karimi, E., 1994. Scrambling to object position in Persian. In: Corver, N., van Riemsdijk, H. (Eds.), Studies in Scrambling: Movement and Nonmovement Approaches to Free Word-order Phenomena. Mouton de Gruyter, Berlin.

Butler, C., 1998. Multi-word phenomena in functional grammar. Revista Canaria de Estudios Ingleses 36, 15-36.

Chang, F., 2009. Learning to order words: a connectionist model of heavy NP shift and accessibility effects in Japanese and English. J. Mem. Learn. 61, 374397.

Chomsky, N., 1970. Remarks on nominalizations. In: Jacobs, R.A., Rosenbaum, P.S. (Eds.), Readings in English Transformational Grammar. Ginn and Co, Waltham, Massachusetts, pp. 184-221.

Chovanec, J., 2008. Enacting an imaginary community: infotainment in on-line minutes-by-minutes sports commentaries. In: Lavric, E., Pisek, G., Skinner, A. Stadler, W. (Eds.), The Linguistics of Football. Narr, Tübingen, pp. 255-268.

Cohen, G., Burke, D.M., 1993. Memory for proper names: a review. Memory 1 (4), 249-263. http://dx.doi.org/10.1080/09658219308258237.

Crystal, D., Davy, D., 1969. Investigating English Style. Longman, London.

Dehghani, Y., 2002. Persian. Lincom Europa, Munich.

Delin, J., 2000. The Language of Everyday Life: An Introduction. Sage, London.

Dik, S.C., 1981. Functional Grammar. Foris, Dordrecht.

Ferguson, C.A., 1983. Sports announcer talk: syntactic aspects of register variation. Lang. Soc. 12 (2), $153-172$.

Foley, W.A., Van Valin, R.D., 1984. Functional Syntax and Universal Grammar. Cambridge University Press, Cambridge.

Ghadessy, M., 1988. The language of written sports commentary: soccer - a description. In: Ghadessy, M. (Ed.), Registers of Written English: Situational Factors and Linguistic Features. Pinter, London, pp. 17-51.

Green, G., 1980. Some wherefores of English inversions. Language 56, 582-602.

Halliday, M.A.K., 1985. Introduction to Functional Grammar. Edward Arnold, London.

Halliday, M.A.K., Hasan, R., 2013. Cohesion in English. Routledge, London.

Halliday, M.A.K., Matthiessen, C.M., 2004. An Introduction to Functional Grammar. Hodder Education, London.

Hanley, R.J., 2011. Why are names of people associated with so many phonological retrieval failures? Psychonomic Bull. Rev. 18, 612-617.

Hawkins, J.A., 1990. A parsing theory of word order universals. Linguist. Inq. 21 (2), 223-261.

Hawkins, J.A., 1994. A Performance Theory of Order and Constituency. Cambridge University Press, Cambridge,.

Hengeveld, K., Mackenzie, J.L., 2008. Functional Discourse Grammar: A Typologically-based Theory of Language Structure. Oxford University Press, Oxford. Holmes, J., 2001. An Introduction to Sociolinguistics. Pearson Education, London.

Jucker, A., 2006. Live text commentaries: read about it while it happens. In: Androutsopoulos, J.K., Runkehl, J., Schlobinski, P., Siever, T. (Eds.), Neuere Entwicklungen in der linguistischen Internetforschung. Olms, Hildesheim, pp. 113-131.

Jucker, A., 2010. 'Audacious, brilliant!! What a strike!': live text commentaries on the Internet as real-time narratives. In: Hoffmann, C.R. (Ed.), Narrative Revisited: Telling a Story in the Age of New Media. Benjamins, Amsterdam, pp. 57-77.

Kayne, R., 1994. The Antisymmetry of Syntax. Cambridge University Press, Cambridge, MA.

Kempen, G., 2000. Could grammatical encoding and grammatical decoding be subserved by the same processing module? Behavioral and Brain Sciences 23, 38-39.

Kempen, G., Harbusch, K., 2004. A corpus study into word order variation in German subordinate clauses: Animacy affects linearization independently of grammatical function assignment. In: Pechmann, T., Habel, C. (Eds.), Multidisciplinary approaches to language production. Mouton de Gruyter, Berlin, pp. 173-181.

Kempen, G., Olsthoorn, N., Sprenger, S.A., 2012. Grammatical workspace sharing during language production and language comprehension: Evidence from grammatical multitasking. Language and cognitive processes 27, 345-380.

Koike, S.S., 1997. Movement in Japanese relative clauses. In: Beerman, D., LeBlanc, D., Van Riemsdijk, H.C. (Eds.), Rightward movement. John Benjamins, Amsterdam/Philadelphia, pp. 171-184.

Kuiper, K., 1996. Smooth talkers: The linguistic performance of auctioneers and sportscasters. Lawrence Erlbaum Associates, Mahwah, NJ.

Kuiper, K., 2009. Formulaic genres. Palgrave Macmillan, Basingstoke.

Kuiper, K., Austin, J.P.M., 1990. They're off and racing now: the speech of the New Zealand race caller. In: Bell, A., Holmes, J. (Eds.), New Zealand ways of speaking English. Multilingual Matters, Bristol, pp. 195-220. 
Kuiper, K., Haggo, D.C., 1985. On the nature of ice hockey commentaries. Association for Canadian Studies in Australia and New Zealand, Christchurch. Kuiper, K., Lewis, R., 2013. The effect of the broadcast medium on the language of radio and television sports commentary genres: The rugby union lineout. Journal of Sports Media 8 (2), 31-52.

Kuno, S., 1978. Japanese: a characteristic OV language. Syntactic Typol. Stud. Phenomenol. Lang., 57-138.

Levelt, W.J.M., 1989. Speaking: From Intention to Articulation. MIT Press, Cambridge, MA.

Mackenzie, J.L., 2005. Incremental functional grammar and the language of football commentary. In: Butler, C.S., Gómez-González, M.D.L.Á., DorvalSuárez, S.M. (Eds.), The Dynamics of Language Use: Functional and Contrastive Perspectives. John Benjamins, Amsterdam/Philadelphia, pp. 113-128. Mackenzie, J.L., Keizer, M.E., 1991. On assigning pragmatic functions in English. Pragmatics 1, 169-215.

Mahowald, K., James, A., Futrell, R., Gibson, E., 2016. A meta-analysis of syntactic priming in language production. J. Mem. Lang 91, 5-27.

Miller, G.A., Chomsky, N., 1963. Finitary models of language users. In: Luce, R.D., Bush, R.R., Galanter, E. (Eds.), Handbook of Mathematical Psychology, vol. 2. John Wiley \& Sons, pp. 419-492.

Newell, A., Simon, H.A., 1972. Human Problem Solving. Prentice Hall, Englewood Cliffs, NJ.

Pawley, A., Syder, F., 1983. Two puzzles for linguistic theory: nativelike selection and nativelike fluency. In: Richards, J., Schmidt, R. (Eds.), Language and Communication. Longman, London, pp. 191-226.

Pawley, A., Syder, F., 2000. The One-clause-at-a-time Hypothesis' Perspectives on Fluency. University of Michigan Press, Ann Arbor, pp. 163-199.

Payne, T.E., 1997. Describing Morphosyntax: A Guide for Field Linguists. Cambridge University Press, Cambridge.

Pérez-Sabater, C., Pena-Martinez, G., Turney, E., Montero-Fleta, B., 2008. A spoken genre gets written: online football commentaries in English, French, and Spanish. Written Commun. 25, 235-261.

Perry, J.R., 2005. A Tajik Persian Reference Grammar. Brill, Leiden.

Ross, J.R., 1967. Constraints on Variables in Syntax. PhD. MIT.

Schwartz, B.L., 2014. Memory for people: integration of face, voice, name, and biographical information. In: Perfect, T.J., Lindsay, D.S. (Eds.), The SAGE Handbook of Applied Memory. Sage, London, pp. 3-19.

Siegel, M., 1999. The Syntactic Processing of Particles in Japanese Spoken Language. In: Paper Presented at the Proceedings of the 13th Pacific Asia Conference on Language, Information and Computation (PACLIC 13), Taipei, Taiwan.

Sprenger, S.A., Bergmann, C., Schmid, M., 2016. The Contribution of Collocations to L1 and L2 Fluency International Symposium on Bilingual and L2 Processing in Adults and Children (ISBPAC). In: University of Kaiserslautern., Kaiserslautern.

Toosarvandanim, M., 2008. Wh-movement and the syntax of sluicing. J. Linguist. 44, 677-722.

Wasow, T., 1997. Remarks on grammatical weight. Lang. Var. Change, 81-105.

Windfuhr, G., 1979. Persian Grammar: History and State of its Study. Mouton, The Hague.

Wray, A., 2002. Formulaic Language and the Lexicon. Cambridge University Press, Cambridge.

Yamashita, H., Chang, F., 2001. ${ }^{\mathrm{a}}$ Long before short ${ }^{\circ}$ preference in the production of a head-final language. Cognition 81, B45-B55. 